Jurnal Pendidikan Matematika : Judika Education

Volume 1, Nomor 2, Juli-Desember 2018

e-ISSN : 2614-6088

p-ISSN : 2620-732X

DOI: https://doi.org/10.31539/judika.v1i2.403

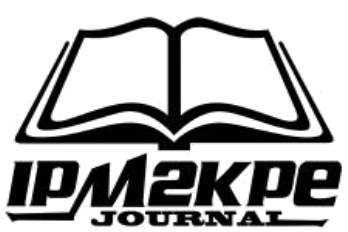

\title{
MISSAURI MATHEMATICS PROJECT BERBASIS SOAL OPEN ENDED TERHADAP KEMAMPUAN KOMUNIKASI MATEMATIKA
}

\author{
Idul adha ${ }^{1}$, Rani Refianti ${ }^{2}$ \\ STKIP PGRI Lubuklinggau ${ }^{1,2}$ \\ Idul_Adha12@yahoo.com
}

\begin{abstract}
ABSTRAK
Tujuan penelitian ini adalah untuk mengetahui pengaruh model missauri mathematic project berbasis soal open ended terhadap kemampuan komunikasi matematika siswa. Populasi penelitian ini adalah seluruh siswa kelas VII SMP Negeri 8 Lubuklinggau tahun pelajaran 2018/2019 sedangkan sampel pada penelitian ini diambil secara random. Teknik pengumpulan data menggunakan teknik tes yang terdiri dari tes uraian yang dilakukan sebanyak dua kali, yakni tes kemampuan awal untuk melihat kemampuan komunikasi matematika sebelum mengikuti pembelajaran dan tes kemampuan akhir sesudah mengikuti pembelajaran. Adapun teknik analisis data dari penelitian ini adalah uji normalitas, uji homogenitas dan uji-t. Berdasarkan hasil analisis uji-t dengan taraf signifikansi $\alpha=0,05$, diperoleh $t_{\text {hitung }}>t_{\text {tabel }}(6,92>1,67)$, sehingga dapat disimpulkan bahwa terdapat pengaruh model pembelajaran missauri mathematic project berbasis soal open ended terhadap kemampuan komunikasi matematika siswa kelas VII SMP N 8 Lubuklinggau.
\end{abstract}

Kata Kunci : Kemampuan Komunikasi, Missauri Mathematic Project, Open Ended

\begin{abstract}
The purpose of this study was to determine the effect of the missauri mathematic project model based on open ended questions on students' mathematical communication skills. The population of this study was all VII grade students of SMP Negeri 8 Lubuklinggau in the 2018/2019 academic year while the samples in this study were taken randomly. Data collection techniques using test techniques consisting of a description test conducted twice, namely the initial ability test to see mathematical communication skills before participating in learning and the final ability test after following learning. The data analysis techniques of this study are the normality test, homogeneity test and t-test. Based on the results of the $t$-test analysis with a significance level $\alpha=0.05$, obtained tcount $>$ ttable (6.92> 1.67), so it can be concluded that there is an influence of missauri mathematical project learning model based on open ended questions on the mathematical communication skills of class students VII SMP N 8 Lubuklinggau.
\end{abstract}

Keywords: Communication Skills, Mathematical Project Missauri, Opend Ended 


\section{PENDAHULUAN}

Matematika sebagai ilmu dasar memiliki peranan penting dalam kehidupan. Ada banyak hal dalam kehidupan sehari-hari yang melibatkan matematika seperti kegiatan jual beli, perbankan, pengukuran dan lain sebagainya. Menurut Sutaro (2005) ilmu pengetahuan yang diperoleh umat manusia saat ini banyak ditunjang oleh penemuan dalam matematika. Hal ini menunjukan bahwa matematika memiliki peran penting dalam perkembangan ilmu pengetahuan dan teknologi. Peraturan Menteri Pendidikan Nasional (Permendiknas) Nomor 22 Tahun 2006 tentang tujuan pembelajaran matematika adalah untuk mencapai kemampuan penalaran, pemecahan masalah, dan komunikasi matematis. Sejalan dengan tujuan pembelajaran matematika tersebut maka komunikasi matematika merupakan bagian penting dari pembelajaran matematika.

$$
\text { Menurut Witri }
$$

kemampuan siswa memecahkan masalah sangat terkait dengan kemampuan siswa dalam membaca dan memahami bahasa soal cerita, menyajikan dalam model matematika, merencanakan perhitungan dari model matematika serta menyelesaikan perhitungan dari soal yang tidak rutin. Hal ini menunjukan pencapaian kemampuan pemecahan masalah memerlukan komunikasi matematika yang baik. Prayitno (2013) menjelaskan, dibeberapa wilayah Indonesia yang berbeda sebagian besar siswa mengalami kesulitan dalam menyelesaikan soal-soal pemecahan masalah dan menterjemahkan soal-soal dalam kehidupan sehari-hari.

Kemampuanpemecahan masalah yang baik membutuhkan komunikasi matematika yang baik, kedua kemampuan ini saling mendukung satu sama lainnya. Izzat (2010) mendapatkan gambaran mengenai lemahnya kemampuan komunikasi matematika siswa dikarenakan pembelajaran yang ada saat ini kurang memberikanperhatikan pengembangan kemampuan komunikasi matematika.

Lebih lanjut hal serupa juga diungkapkan oleh Sunadi (2014) yang melihat kebanyakan siswa mengalami kesulitan dalam mengaplikasikan matematika kedalam situasi kehidupan nyata. Hal tersebut dikarenakan kemampuan komunikasi matematika siswa belum dilatih secara maksimal.Banyaknya permasalahan dalam pembelajaran matematika menyebabkan prestasi matematika siswa rendah.

Pada forum Internasional Mathematiical Olympiade (IMO) menunjukan hasil yang jauh dari menggembirakan, rendahnya hasil matematika di Indonesia salah satunya disebabkan oleh rendahnya kualitas pembelajaran yang diselenggarakan guru di sekolah, kurang tepatnya pendekatan pembelajaran yang dipilih guru bermuara pada kurang efektifnya 
pembelajaran yang dikembangkan di kelas Faradhila, et al (2013).

$$
\text { Sejalan dengan yang }
$$
diungkapkan oleh Hasratuddin (2010) praktek pembelajaran di sekolahsekolah yang berlangsung selama ini, dan hampir di semua jenjang pendidikan, pada umumnya berlangsung satu arah, yaitu guru sebagai pusat pembelajaran (teacher centered). Matematika disajikan sebagai produk jadi siap pakai sehingga siswa dalam pengerjaan matematika itu sendiri hanya perlu mengikuti prosedur rutin sesuai dengan yang telah guru jelaskan.

Melihat

pentingnya

pembelajaran matematika dalam kehidupan serta rendahnya prestasi matematika terutama pada kemampuan komunikasi matematika maka diperlukan suatu solusi yang dapat memfasilitasi agar tujuan dari pembelajaran matematika dapat tercapai. Model Missauri Mathematic Project merupakan salah satu model pembelajaran inovatif yang dapat memfasilitasi kemampuan komunikasi matematika siswa.

Menurut Wulandari \& Ansori (2013) karakteristik dari Missauri Mathematic Projectadalah lembar kerja proyek, dimana siswa diberikan lembar kerja proyek yang berisikan soal-soal pada langkah kerja kooperatif, kerja mandiri dan penugasan. Adapun tujuan dari lembar kerja proyek ini adalah untuk memperbaiki komunikasi, penalaran, keterampilan membuat keputusan dan keterampilan memecahan masalah.

Untuk kemampuan komunikasi matematikatidak hanya dibutuhkan pemilihan model pembelajaran yang tepat, tetapi pemilihan soal yang tepat juga diperlukan guna menunjang keberhasilan pembelajaran. Missauri Mathematic Project menekankan pada pemberian soal-soal latihan sehingga tipe soal yang diberikan perlu menjadi pertimbangan dalam menentukan keberhasilan siswa pada proses pembelajaran.

Pemberian soal opend ended merupakan salah satu satu solusi alternatif dalam pembelajaran yang menekankan pada proses latihan soalsoal. Menurut Saniah (2016) soal opend ended berupa soal yang meminta siswa untuk menganalisis, menjelaskan,dan membuat dugaan, tidak hanya menyelesaikan, menemukan atau menghitung.

Pembelajaran menggunakan soal opendended menyediakan kesempatan seluas-luasnya agar aktivitas dan pemikiran matematis siswa dapat berkembang.

Hal ini sangat diperlukan bagi setiap siswa agar mereka memiliki kebebasan individu untuk mengembangkan kemampuan penalaran, pemecahan masalah dan komunikasi matematis (Melianingsi \& Sugiman, 2015). Soal opend ended merupakan soal dengan banyak jawaban benar, yang memberikan kebebasan pada siswa menggunakan berbagai strategi dalam upayah 
mengasah kemampuan komunikasi matematika siswa.

Sebelumnya penelitin mengenai menggunakan model missauri mathematics project telah banyak dilakukan salah satunya penelitian dilakukan oleh Arifa Rahmi \& Depriwanta Rahmi dengan judul penerapan model missauri mathematics project terhadap kemampuan komunikasi matematika siswa SMK Dwi Sejahtera Pekanbaru yang menunjukan hasil rata-rata kelas eksperimen lebih dari kelas kontrol. Adapun perbedaan antara penelitian yang dilakukan peneliti dengan penelitian sebelumnya yakni dalam penelitian ini peneliti menggunakan soal opend ended tujuannya adalah agar kemampuan komunikasi matematika siswa dapat lebih terlatih.

Tujuan penelitian ini adalah untuk mengetahui pengaruh model missauri mathematic project berbasis soal open ended terhadap kemampuan komunikasi matematika siswa.

\section{METODE PENELITIAN}

Jenis penenlitian ini adalah eksperimen murni yang melibatkan dua kelas yang berbeda. kelas eksperiment diberi bembelajaran menggunakan Missauri Mathematic Project sedangkan kelas kontrol diberi pembelajaran konvensional.

Populasi dalam penelitian ini adalah seluruh siswa kelas VII SMP Negeri 8 Lubuklinggau Tahun Pelajaran 2017/2018. Sampel dalam penelitian ini diambil secara acak (sample random) dengan cara pengundian. Pada teknik ini semua anggota dalam populasi mempunyai probabilitas atau kesempatan yang sama untuk dipilih menjadi sampel dan dalam hal ini seluruh siswa kelas VII SMP Negeri 8 Lubuklinggau Tahun Pelajaran 2017/2018 memiliki peluang yang sama untuk menjadi sampel.

Teknik pengumpulan data yang digunakan dalam penelitian ini adalah teknik tes. Tes digunakan untuk komunikasi matematika. Tes dilakukan sebanyak dua kali yaitu sebelum (pretest) dan sesudah (posttest) siswa diberikan treatment (perlakuan) dengan model pembelajaran Missauri Mathematic Project. Teknik analisis data yang digunakan adalah uji normalitas, uji homogenitas dan uji-t.

\section{HASIL PENELITIAN}

Penelitian ini dilaksanakan pada tanggal 2 Mei sampai dengan 30 Mei 2018, Sebelum penelitian dilakukan terlebih dahulu dilakukan uji coba instrument. Tujuan dilaksanakan uji coba instrumen adalah untuk mengetahui instrumen mana saja yang dapat digunakan pada penelitian.

Dari tujuh instrumen yang diujicobakan terdapat enam instrumen yang valid dan dapat digunakan. Jumlah pertemuan yang dilaksanakan pada penelitian ini sebanyak lima pertemuan yang terdiri dari satu kali 
pre-test, tiiga pertemuan atau perlakuan pada proses pembelajaran yang menggunakan model misaauri mathematic project dan satu pertemuan post-test.

Pretes bertujuan mengetahui kemampuan awal siswa sebelum mendapatkan perlakuaaan pembelajaran menggunakan model missaur mathematic project dan post test bertujuan untuk mengetahui kemampauan akhir siswa setelah pembelajaran menggunakan missaur mathematic project, sedangkan pembelajaran kelas kontrol dilakukan oleh guru menggunakan metode konvensional. Berikut data hasil rekapitulasi pre-tes dapat dilihat pada tabel di bawah ini

Tabel 1Rekapitulasi Data Hasil Pre-test

\begin{tabular}{cccc}
\hline Kelas & $\mathrm{N}$ & $\bar{x}$ & $S$ \\
\hline Eksperimen & 26 & 14,76 & 4,81 \\
\hline Kontrol & 27 & 13,14 & 4,73 \\
\hline
\end{tabular}

Berdasarkan tabel di atas dapat dijabar bahwa terdapat 26 siswa kelas eksperimen yang mengikuti pretest dengan rata-rata 14,76 dan simpangan baku 4,81 sedangkan pada kelas kontrol terdapat 27 siswa yang mengikuti tes dengan rata-rata 13,14 dan simpangan baku 4,73. Ini menunjukan rata-rata dan simpangan baku kelas eksperimen lebih dari kelas kontrol.
Tabel 2. Rekapitulasi data hasil post test

\begin{tabular}{cccc}
\hline Kelas & $\mathrm{N}$ & $\bar{x}$ & $\mathrm{~S}$ \\
\hline Eksperimen & 27 & 32,44 & 4,53 \\
\hline Kontrol & 27 & 24,22 & 4,19 \\
\hline
\end{tabular}

Berdasarkan tabel di atas dapat dijabar bahwa terdapat 27 siswa kelas eksperimen yang mengikuti pretest dengan rata-rata 32,44 dan simpangan baku 4,53 sedangkan pada kelas kontrol terdapat 27 siswa yang mengikuti tes dengan rata-rata 24,22 dan simpangan baku 4,19. Adapun perbandingan kemampuan komunikasi matematika siswa saat pre-test dan post-test pada kelas eksperimen dan kelas kontrol dapat dilihat pada grafik di bawah ini :

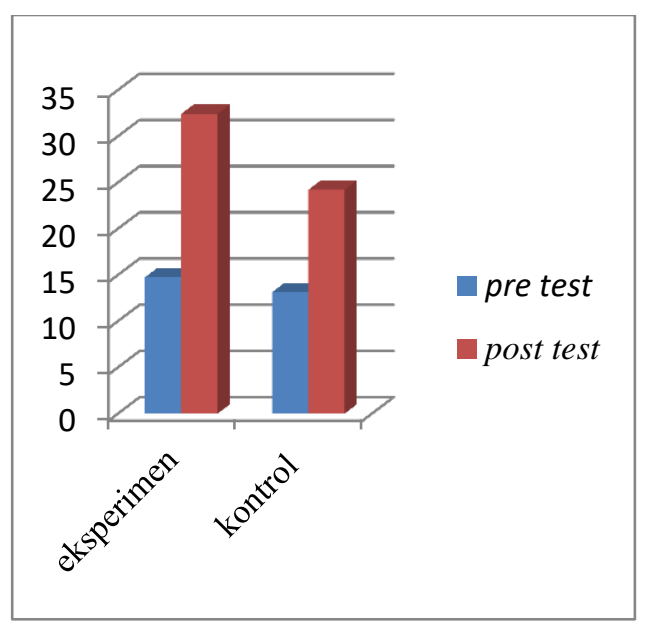

Grafik 1 Perbandingan pre-test dan posttest

Analisis Inferensial data pre-test terdiri dariuji normalitas, uji normalitas dan uji perbedaan dua ratarata.Uji normalitas digunakan untuk mengetahui normal atau tidaknya data ang diperoleh. Pada uji normalitas menggunakan uji kecocokan chi 
kuadrat $\left(\chi^{2}\right)$ dengan taraf signifikansi $\alpha=0,05$, jika $\chi^{2}$ hitung $<\chi^{2}$ tabel maka data tersebut dinyatakan berdistribusi normal. Rekapitulasi hasil uji normalitas data pre-test pada kelas eksperimen dan kelas kontrol dapat dilihat pada tabel di bawah ini

Tabel 3 Rekapitulasi Hasil Uji Normalitas data Pre-test

\begin{tabular}{cccc}
\hline Kelas & $\chi^{2}$ hitung & $\chi^{2}$ tabel & Simpulan \\
\hline Eksperimen & 4,14 & 11,07 & Normal \\
\hline Kontrol & 4,87 & 11,07 & Normal \\
\hline
\end{tabular}

Dari data di atas dapat dilihat bahwa $\chi_{\text {hitung }}^{2}$ kelas eksperimen dan kelas kontrol kurang dari $\chi_{\text {tabel }}^{2}$, sehingga kedua kelas tersebut berdistribusi normal. Uji homogenitas ini dilakukan untuk mengetahui apakah data pre-test kelas eksperimen dan kelas kontrol memiliki varians yang homogen atau tidak homogen. Rekapitulasi uji homogenitas data pretest pada kelas eksperimen dan kelas kontrol dapat dilihat pada tabel di bawah ini:

Tabel 4 Rekapitulasi Hasil Uji Homogenitas Data Pre-test

\begin{tabular}{cccc}
\hline Data & $F_{\text {hitung }}$ & $\mathrm{Dk}$ & $F_{\text {tabel }}$ \\
\hline Pre-test & 1,03 & $(25: 26)$ & 1,94 \\
\hline
\end{tabular}

Dari data di atas dapat dilihat bahwa $F_{\text {hitung }}$ lebih dari $F_{\text {tabel, }}$, sehingga diperoleh bahwa kedua varians kelas eksperimen dan kelas kontrol homogen. Uji kesamaan dua rata-rata menggunakan uji-t $(t)$. Kriteria pengujian hipotesis yang digunakan oleh peneliti adalah terima $\mathrm{H}_{\mathrm{o}}$ jika $t_{\text {hitung }}<t_{\text {tabel }}$. Rekapitulasi hasil perhitungan uji kesamaan dua rata-rata dapat dilihat pada tabel di bawah ini.

Tabel 5 Rekapitulasi Hasil Uji Kesamaan Dua Rata-rata

\begin{tabular}{cccc}
\hline Data & $t_{\text {hitung }}$ & $t_{\text {tabel }}$ & Kesimpulan \\
\hline Pre-test & 1,24 & 2,00 & $\mathrm{H}_{\mathrm{o}}$ diterima \\
\hline
\end{tabular}

Dari tabel di atas dapat dilihat bahwa $t_{\text {hitung }}<t_{\text {tabel }}$ sehingga $\mathrm{H}_{\mathrm{o}}$ diterima, dapat diperoleh kesimpulan bahwa data pre-test terhadap kemampuan komunikasi matematika siswa tidak memiliki perbedaan antara kelas eksperimen dan kelas kontrol.

Analisis Inferensial data post-test terdiri dari uji Normalitas, uj homogenitas dan uji perbedaan dua rata-rata. Rumus yang digunakan untuk menghitung normalitas data adalah uji kecocokan chi kuadrat $\left(\chi^{2}\right)$ dengan taraf signifikansi $\alpha=0,05$, jika $\chi^{2}{ }_{\text {hitung }}<\chi_{\text {tabel }}^{2}$ maka data tersebut dinyatakan berdistribusi normal. Rekapitulasi hasil uji normalitas data post-test pada kelas eksperimen dan kelas kontrol dapat dilihat pada tabel di bawah ini.

Tebel 6 Rekapitulasi Hasil Uji Normalitas Data Post-test

\begin{tabular}{cccc}
\hline No & Kelas & $\chi_{\text {hitung }}^{2}$ & $\chi_{\text {tabel }}^{2}$ \\
\hline 1 & Eksperimen & 1,57 & 11,07 \\
\hline 2 & Kontrol & 6,72 & 11,07 \\
\hline
\end{tabular}

Dari data di atas dapat dilihat bahwa $\chi^{2}$ hitung kelas eksperimen dan kelas kontrol kurang dari $\chi_{\text {tabel }}^{2}$, sehingga kedua kelas tersebut berdistribusi normal. Setelah kita melakukan uji normalitas data, maka selanjutnya kita melakukan 
uji homogenitas varians, uji homogenitas ini dilakukan untuk mengetahui apakah data post-test kelas eksperimen dan kelas kontrol memiliki varians yang homogen atau tidak homogen. Rekapitulasi hasil uji homogenitas data post-test pada kelas eksperimen dan kelas kontrol dapat dilihat pada tabel di bawah ini

Tabel 7 Rekapitulasi Hasil Uji

Homogenitas Data Post-test

\begin{tabular}{cccc}
\hline Data & $F_{\text {hitung }}$ & $F_{\text {tabel }}$ & Kesimpulan \\
\hline Post-test & 1,16 & 1,93 & Homogen \\
\hline
\end{tabular}

Dari data di atas dapat dilihat bahwa $F_{\text {hitung }}$ kurang dari $F_{\text {tabel }}$, sehingga diperoleh kesimpulan bahwa varians kelas eksperimen dan kelas kontrol homogen. Pasangan hipotesis yang digunakan pada post-test adalah:

$\mathrm{H}_{\mathrm{o}}$ : Kemampuan komunikasi matematika siswa kelas eksperimen kurang dari atau sama dengan kelas kontrol $\left(\mu_{1} \leq \mu_{2}\right)$

$\mathrm{H}_{\alpha}$ : Kemampuan komunikasi matematika siswa kelas eksperimen lebih dari kelas kontrol $\left(\mu_{1}>\mu_{2}\right)$

Kriteria pengujian hipotesis yang digunakan adalah terima $\mathrm{H}_{\mathrm{o}}$ jika $t_{\text {hitung }}$ kurang dari atau sama dengan $t_{\text {tabel }}$ dan sebaliknya terima $\mathrm{H}_{\alpha}$ jika $t_{\text {hitung }}$ lebih dari $t_{\text {tabel }}$. Rekapitulasi hasil perhitungan uji perbedaan dua ratarata hasil post-test dapat dilihat pada di bawah ini.
Tabel 8 Rekapitulasi Hasil Uji Perbedaan Dua Rata-rata

\begin{tabular}{cccc}
\hline Data & $t_{\text {hitung }}$ & $t_{\text {tabel }}$ & Kesimpulan \\
\hline Post-test & 6,92 & 1,67 & $\mathrm{H}_{\mathrm{o}}$ ditolak \\
\hline
\end{tabular}

Dari tabel di atas diperoleh bahwa terima $\mathrm{H}_{\alpha}$, karena $t_{\text {hitung }}>t_{\text {tabel }}$, sehingga hipotesis yang diajukan dalam penelitian ini terbukti. Jadi dapat disimpulkan bahwa "Terdapat pengaruh model pembelajaran missauri mathematic project berbasis soal opend ended terhadap kemampuan komunikasi matematika siswa di kelas VII

\section{PEMBAHASAN}

Penelitian ini dilakukan di SMP Negeri 8 Lubuklinggau dan dilaksanakan langsung oleh peneliti. Dalam penelitian ini, peneliti menggunakan model missauri mathematic project berbasis soal opend ended dengan tujuan untuk mengetahui pengaruh model tersebut terhadap kemampuan komunikasi siswa SMP N 8 Lubuklinggau. Penelitian dilakukan sebanyak lima kali pertemuan yang terdiri dari pretest, perlakukan pembelajaran menggunakan model missauri mathematic project sebanyak tiga kali pertemuaan dan post test.

Pembelajaran pada kelas eksperimen dilakukan oleh peneliti menggunakan model missauri mathematic project sedangkan pembelajaran pada kelas kontrol dilakukan oleh guru mata pelajaran matematika yang bersangkutan 
menggunakan metode konvensional, selanjutnya hasil dari kedua kelas ini dibandingkan untuk mengetahui ada tidaknya pengaruh model missauri mathematic project berbasis soal opend ended terhadap kemampuan komunikasi matematika siswa. Berdasarkan hasil post test atau tes akhir diketahui bahwa skor rata-rata kelas eksperimen lebih dari kelas kontrol yakni kelas eksperimen sebesar 32,44 sedangkan kelas kontrol sebesar 24,22. Analisis Inferensial data post-test terdiri dari uji Normalitas, uj homogenitas dan uji perbedaan dua rata-rata.

Berdasarkan hasil uji normalitas data post-test diketahui $\chi^{2}$ hitung kelas eksperimen dan kelas kontrol kurang dari $\chi^{2}$ tabel , sehingga kedua kelas tersebut berdistribusi normal. Pada uji homogenitas diketahui $F_{\text {hitung }}$ kurang dari $F_{\text {tabel }}$, sehingga diperoleh kesimpulan bahwa varians kelas eksperimen dan kelas kontrol homogen. Sedangkan pada uji perbedaan dua rata-rata diperoleh $\mathrm{t}_{\text {hitung }}>\mathrm{t}_{\text {tabel }}$, sehingga hipotesis yang diajukan dalam penelitian ini terbukti. Jadi dapat disimpulkan bahwa "Terdapat pengaruh model pembelajaran missauri mathematic project berbasis soal opend ended terhadap kemampuan komunikasi matematika siswa di kelas VII

\section{SIMPULAN}

Berdasarkan hasil penelitian dan pembahasan, dapat disimpulkan bahwa terdapat pengaruh model model missauri mathematic project berbasis soal open ended terhadap kemampuan komunikasi matematika siswa tahun pelajaran 2017/2018.

\section{DAFTAR PUSTAKA}

Anisa, W. (2014). Peningkatan Kemampuan Pemecahan Masalah dan Komunikasi Matematika Melalui Pembelajaran Matematika Realistik Indonesia Untuk Siswa SMP Negeri di Kabupaten Garut. Jurnal Pendidikan Keguruan 1(1)

Djahuno, S. (2016). Pengembangan Soal Opend Ended pada Pokok Bahasan Barisan dan Deret Bilangan di Kelas IX A SMP Negeri 2 Tolitoli. Jurnal Kreatif Taduloka Online 4(6)

Faradhilla, N. (2013). Eksperiment Model Pembelajaran Missouri Mathematics Project (MMP) Pada Materi Pokok Luas Permukaan Serta Volume Prisma dan Limas Ditinjau Dari Kemampuan Spasial Siswa Kelas VIII Semester Genap SMP Negeri 2 Kartasura Tahun Ajaran 2011/2012. Jurnal Pendidikan Matematika Solusi 1(1); 67-74.

Hadi, S. (2005). Pendidikan Matematika Realistik dan Implementasinya. Banjarmasin : Tulip.

Hasratuddin. (2010). Meningkatkan Kemampuan Berfkir Kritis Siswa SMP Melalui Pendekatan Matematika Realistik. Jurnal Pendidikan Matematika. 4 (2) 
Izzat \& Sryadi. (2010). Komunikasi Matematika dan Pendidikan Matematika Realistik. Jurnal Pendidikan Matematika. 1(1)

Melianingsi, N. (2015). Keefektifan pendekatan opend ended dan problem solving pada pembelajaran bangun ruang sisi datar. Jurnal Riset Pendidikan Matematika. 2(1).

Permendiknas. (2006).Peraturan Menteri Pendidikan Nasional Nomor 22, Tahun 2006, tentang standar isi.

Prayitno. (2013). Indentifikasi Indikator Kemampuan Komunikasi Matematis Siswa dalam Menyesaikan Soal Matematika Berjenjang pada tiap-tiap Jenjangnya. Jurnal KNPM. Himpunan Matematika Indonesia 1(1).

Sunadi. (2014). Pembelajaran Matematika Realistik Untuk Meningkatkan Kemampuan Komunikasi Matematika Siswa. Prosiding Nasinal Pendidikan Matematika di STKIP Siliwangi Bandung 1(1).

Wulandari, Tatik \& Hidayah A. (2013). Pengaruh Model Pembelajaran Missauri Mathematic Projec Terhadap Kemampuan Siswa Dalam Memecahkan Masalah. Edu-Mat Jurnal Pendidikan Matematika. 1(1). 